\title{
A REPORT OF A WORKING GROUP OF THE BRITISH CARDIAC SOCIETY: CARDIAC REHABILITATION SERVICES IN THE UNITED KINGDOM 1992
}

\section{Introduction}

In 1989 the British Cardiac Society undertook a survey of cardiac rehabilitation services in the United Kingdom. ${ }^{1}$ This showed that less than half the health districts had an established service but a further third expressed an interest in having one. Subsequently the British Heart Foundation undertook to fund 20 new cardiac rehabilitation programmes in the United Kingdom each year for a two year period as a pump priming exercise. This has resulted in an appreciable increase in the number of rehabilitation programmes available and the British Cardiac Society and British Heart Foundation decided to undertake a further survey, which is the basis of the current report.

\section{Method}

In November 1992 survey forms were sent to contacts in all 218 United Kingdom health districts or boards in existence at that time: these did not include the Isle of Man or the Channel Islands. After two reminders and telephone follow up a response rate of $100 \%$ was achieved (that is, at least one form from every district). Further enquiries were necessary in districts with more than one hospital, specifically in Wales, Scotland, and Northern Ireland. No survey date was indicated on the form but figures for "the last year" are assumed to have been for 1992. The separate survey of technical facilities carried out by the British Cardiac Society in 1992 also enquired into cardiac rehabilitation and some of the data have been included in this report.

\section{Results}

Of the 218 districts contacted in the United Kingdom (which included a total of 252 hospitals) $161(74 \%)$ of the districts had cardiac rehabilitation facilities. Inpatient provision was present in 86 , outpatient in 151 , and both in 75 . In all we counted 186 rehabilitation programmes (some districts had more than one hospital involved); of the 57 districts without a programme only two would not have found a programme useful and nine were uncommitted in this respect.

\section{REGIONAL DISTRIBUTION}

Rehabilitation programmes were found in all regions, but the metropolitan regions were relatively under-provided (North East Thames 8/16 districts without a programme; North West Thames 6/13; South East Thames 3/15; South West Thames 4/13) compared with the rest of the country. In Wales, which has 18 district hospitals, there are only nine programmes. Cardiothoracic centres without a programme at the time of the survey included Bristol, Hull, Manchester Central, Papworth, the Royal Brompton and National Heart Hospital, and the Hammersmith Hospital.

HOW LONG HAS THE PROGRAMME BEEN IN EXISTENCE?

Figure 1 shows the number of rehabilitation
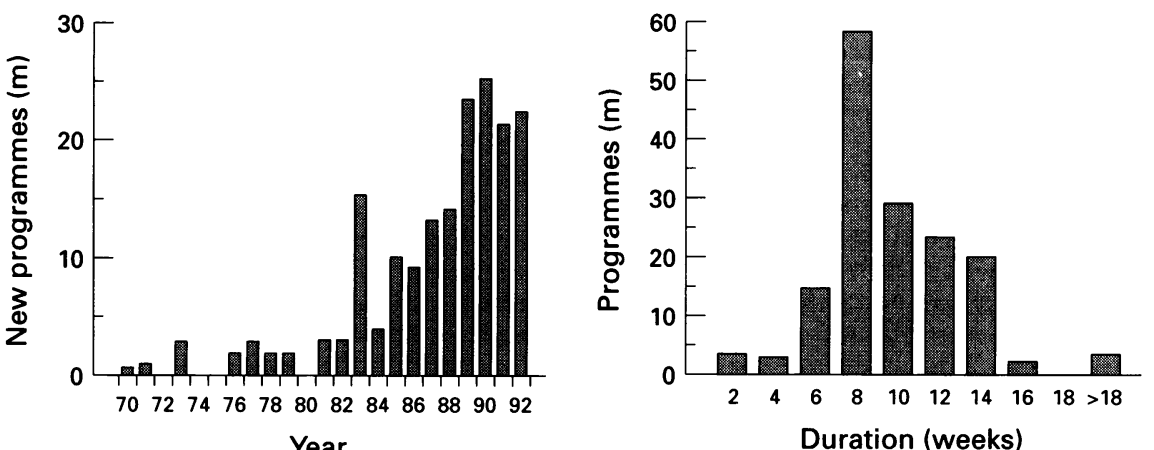

Figure 1 Number of new cardiac

rehabilitation programmes established each year in the United Kingdom, showing the rapid increase in the number of new programmes resulting from the Chest Heart Stroke Association and British Heart Foundation initiative in 1989.

programmes established each year over the past 23 years. It reflects the considerable increase in the number of programmes over the past 5 years, which in part is an effect of the British Heart Foundation initiative.

FUNDING

Although most were directly funded by the NHS (106) a sizeable minority were either partly (40) or wholly funded (18) from charitable sources; seven were funded from soft money or a specific grant. There were support groups in 117 hospitals (63\%).

\section{ORGANISATION}

Virtually all the programmes were hospital based with only two being held at sports centres. Ten further programmes use sports centres as well. Direct referrals from GPs were accepted by 91 programmes $(49 \%)$. Only 35 courses did not cater for patients after bypass surgery but many (81) did not cater for patients after angioplasty. The estimated proportion of the different conditions treated was imprecise but suggested the following: post-infarct $76 \%$; post-CABG $18 \%$; post-angioplasty $2 \%$; post-angina $2 \%$. Sixty seven programmes gave an age limit as follows: two excluded patients over the age of 60,27 excluded those over 65,31 excluded those over 70, six excluded those over 75 , and 1 excluded those over 80 . Only one recently established programme had not yet catered for women. There was no relation between the presence of an age limit and the numbers treated. Eighty six programmes started less than 4 weeks and only one started more than 10 weeks from the cardiac event. Figure 2 shows the duration of programmes.

NUMBER OF PATIENTS TREATED

Nearly half of all forms returned gave estimated rather than actual patient numbers for the preceding year, and 39 hospitals with rehabilitation did not give any patient numbers (10 of these had been established for less than 12 months). The total number of patients treated in 1992 at the 135 rehabilitation programmes which stated patient numbers and had existed for 12 months or
Figure 2 Duration of cardiac rehabilitation programmes in the United Kingdom. Most last 2-3 months.

more was 22 966. A further 1000 patients were treated by the 12 programmes that had been established twelve months or less. There was some general relation between the patient numbers treated per district and the size of the health district; on average the 60 health districts serving a population of up to 248000 had treated 143 patients; 62 health districts serving between 248000 and 534000 treated 181 patients and 10 health districts with populations over 534000 treated 344 patients in $1992(\mathrm{P}=0 \cdot 01)$.

\section{REHABILITATION STAFF}

Figure 3 shows the involvement of the different disciplines in the rehabilitation programmes. For $92 \%$ of programmes the numbers of hours per week was stated: on average it was physiotherapists $7 \cdot 5$; nurses 18.6; occupational therapists $8 \cdot 3$; dieticians $2 \cdot 5$. Full time nurses were employed in 35 programmes $(19 \%)$ whereas only five programmes had a full time physiotherapist. There was a weak relation between the numbers of patients treated and the total staff hours committed to the programme $\left(r^{2}=0.16 ; P<0.001\right)$

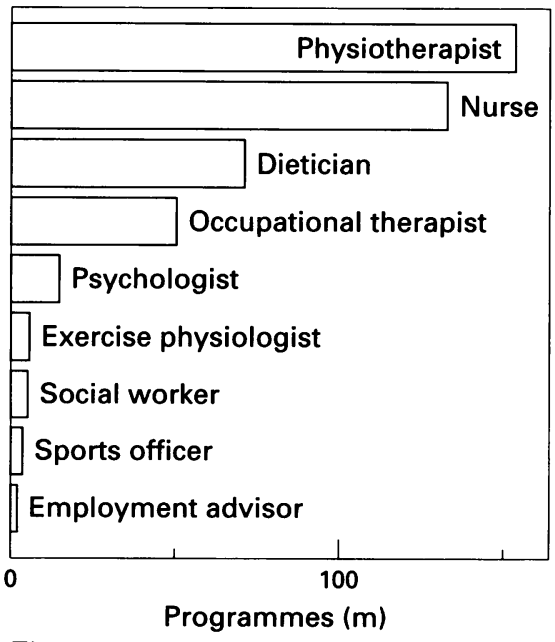

Figure 3 Involvement of paramedical workers in cardiac rehabilitation programmes in the United Kingdom $(n=186)$. 
DROP OUT RATE

This was given by 112 programmes but only 45 were able to give an exact figure. The rates were as follows: $<5 \%, 29$ programmes; $5-10 \%, 19 ; 10-15 \%$, 20 $15-20 \%, 16 ;>20 \%, 28$ programmes. Almost twice as many patients dropped ou for "other" reasons rather than for medica reasons. There was no apparent relation between a high drop-out rate and the number of patients treated or the number of sup port staff. In general the rates were higher in those programmes that gave exact patien numbers, suggesting that the remainder may have underestimated the problem. The average overall was $18 \%, 7 \%$ for medical and $11 \%$ for other reasons. The very high dropout rates in some programmes (10 had rates greater than $25 \%$ ) deserve further scrutiny and may be due to the inclusion of all patients eligible for rehabilitation rather than those selected clinically.

\section{Comment}

This survey gives an overview of the current provision of cardiac rehabilitation in the United Kingdom, and although there has been a striking increase in activity there are still areas of concern. Since $1989^{1}$ there has been a significant increase in the number of programmes and patients treated, but London and Wales lag behind the rest of the country. Few centres are able to give accurate figures for the numbers of patients treated and the staff time involved, and a standard dataset to audit activity as suggested by the BCS working party ${ }^{1}$ report is long overdue. Further investigation of the high drop-out rate is also needed, as well as what proportion of eligible patients actually take part (to answer the criticism that programmes may select only low-risk patients for whom the benefit may be marginal). Finally, there is a clear need to ensure that cardiac rehabilitation forms part of the core service in future contractual arrangements, currently $38 \%$ of programmes depend on non-NHS funding.

Members of working group: C Davidson, $\mathrm{K}$ Reval, D A Chamberlain, B Pentecost, J Parker.

Horgan J, Bethell H, Carson P, Davidson C, Julian D, Mayou RA, Nagle R. Workin party report on cardiac rehabilitation. $B$ Heart $\mathcal{f} 1992 ; 67: 412-8$. 